\title{
DCEFER/13935-TI
}

\section{Electrophilic Metal Alkyl Chemistry in New Ligand Environments.}

DE-FG02-88ER13935. Richard F. Jordan, P.I.

1992 Annual Report and 1993 Research Plan

DOE/ER/13935--T1

9/15/92

DE93 005125

Introduction and Objectives. This report covers research performed during the period 1/1/92 $9 / 15 / 92$. The principal objective of this project is to develop new types of electrophilic metal alkyl complexes for fundamental studies in olefin polymerization and $\mathrm{C}-\mathrm{H}$ activation catalysis. Most of our work during the current year has focused on the synthesis and chemistry of $\mathrm{d}^{0}$, group 4 metal alkyls of general type $\left(\mathrm{N}_{4}\right) \mathrm{M}(\mathrm{R})^{+}(\mathbf{1})$ and $\left(\mathrm{N}_{4}\right) \mathrm{M}(\mathrm{R})(\mathrm{L})^{+}(\mathrm{L}=$ labile ligand, 2$)$ which incorporate dianionic, $12-$ electron donor, tetradentate, $\mathrm{N}_{4}$ macrocyclic ligands (abbreviated $\mathrm{N}_{4}{ }^{2-}$ ). We are interested to know how the chemistry of such complexes compares with that which we developed earlier for $\mathrm{Cp}_{2} \mathrm{M}(\mathrm{R})^{+}$ complexes (3), in order to understand ligand effects on reactivity and to develop new reaction chemistry.

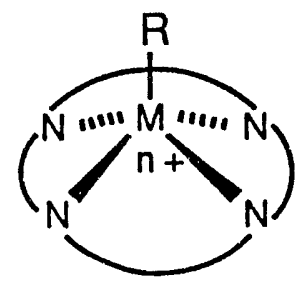

1

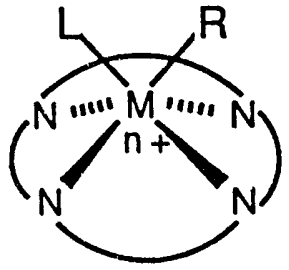

2

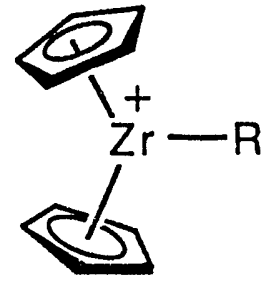

3

Results. We have prepared a series of $\mathrm{N}_{4}{ }^{2-}$ ligands via modified literature methods. The (Me8dibenzo-taa) ${ }^{2-}$ ligand (4) is similar to ligands used in the past, but is more highly methylated for increased solubility and NMR spectra simplification. The $\left(\mathrm{R}_{4}-\left(\mathrm{CH}_{2} \mathrm{CH}_{2}\right)_{2} \text {-taa }\right)^{2-}$ ligands (5) are prototypes for chiral ligands (6) which we intend to develop later.<smiles></smiles>

4, $R_{1}=R_{2}=M e$<smiles></smiles>

$5, R=M e, E t$

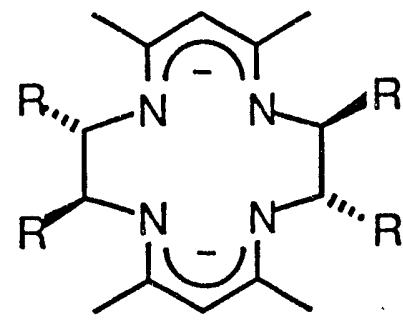

6

Two general routes to $\mathrm{N}_{4} \mathrm{M}(\mathrm{R})_{2}$ complexes have been developed. These are (i) generation of $\left(\mathrm{N}_{4}\right) \mathrm{MX} 2$ followed by alkylation (eq 1), and (ii) direct synthesis via $\mathrm{RH}$ elimination from $\mathrm{MR}_{4}$ and $\left(\mathrm{N}_{4}\right) \mathrm{H}_{2}$ (eq 2). 
The first is very general, since the $\mathrm{N}_{4}{ }^{2-}$ dianions can be isolated and many $\mathrm{RLi}$ or $\mathrm{RMgX}$ reagents can be used, and the second avoids the use of Lewis basic solvents 'which can complicate the chemistry in certain cases. These routes also work well for the $\mathrm{Hf}$ analogues, but not for the Ti analogues.

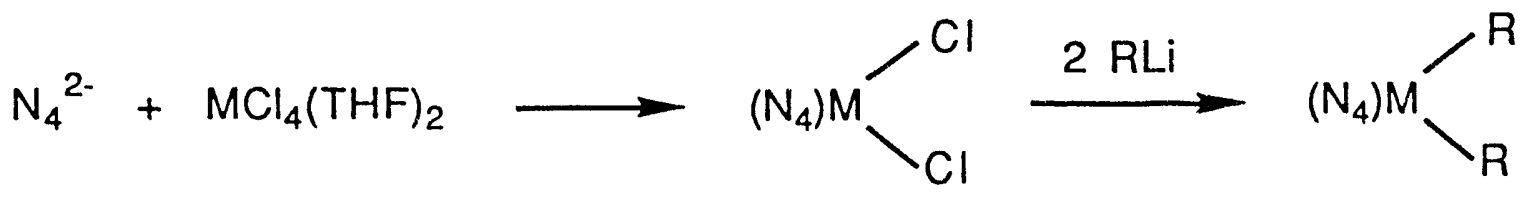

$$
\begin{aligned}
& \mathrm{MR}_{4}+\mathrm{H}_{2}\left(\mathrm{~N}_{4}\right) \underset{-2 \mathrm{R}-\mathrm{H}}{\longrightarrow}\left(\mathrm{N}_{4}\right) \mathrm{M}_{\mathrm{R}}^{\mathrm{R}}
\end{aligned}
$$

The X-ray structure of a representative $\left(\mathrm{N}_{4}\right) \mathrm{MR}_{2}$ complex, $\left(\mathrm{Me}_{4}-\left(\mathrm{CH}_{2} \mathrm{CH}_{2}\right)_{2}\right.$-taa) $\mathrm{Zr}\left(\mathrm{CH}_{2} \mathrm{Ph}\right)_{2}$, confirms the cis, saddle-type structure, which is imposed by the fact that $\mathrm{Z}^{4+}$ is too large to fit in the $\mathrm{N}_{4}$ plane.

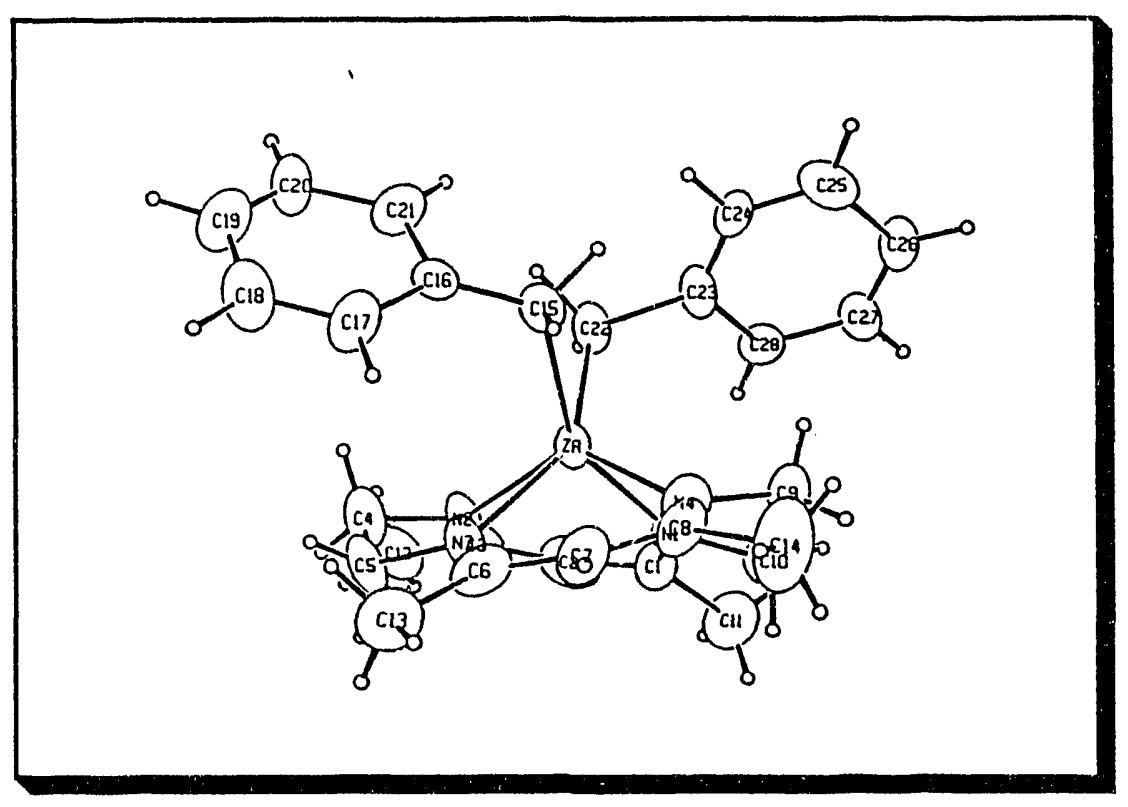

In initial work we have discovered that cationic complexes of types $\mathbf{1}$ and 2 can be generated in several ways. The reaction of (Me8-dibenzo-taa) $\mathrm{ZrMe}_{2}$ with the strong Lewis acid $\mathrm{B}\left(\mathrm{C}_{6} \mathrm{~F}_{5}\right)_{3}$ results in formation of an adduct which catalyzes ethylene polymerization. It is believed that the active species is the ion-pair (Me8-dibenzo-taa) $\mathrm{ZrMe}^{+} \mathrm{MeB}\left(\mathrm{C}_{6} \mathrm{~F}_{5}\right)_{3}$ - formed by full $\mathrm{Me}^{-}$abstraction. This is an important result as it supports our major working hypothesis that cationic complexes of type will be highly electrophilic like the $\mathrm{C}_{2} \mathrm{M}(\mathrm{R})^{+}$analogues. Several base-stabilized cations $\left(\mathrm{N}_{4}\right) \mathrm{M}(\mathrm{R})(\mathrm{L})^{+} \mathrm{BPh}_{4}$ - have been prepared by oxidation or protolysis of $\left(\mathrm{N}_{4}\right) \mathrm{MR}_{2}$ complexes and characterized. These first 
generation, base-stabilized complexes are not very reactive however, most likely because the ligands are not very labile, and we have therefore turned our attention to the preparation of base-free systems. One such cation, $\left(\mathrm{R}_{4}-\left(\mathrm{CH}_{2} \mathrm{CH}_{2}\right)_{2}\right.$-taa $) \mathrm{Zr}\left(\mathrm{CH}_{2} \mathrm{SiMe}_{3}\right)^{+}$(dicarbollide) ${ }_{2} \mathrm{Co}^{2-}$ has been prepared and is under study presently.

Summary. We have worked out methods for the efficient synthesis of various $\mathrm{N}_{4}{ }^{2-}$ macrocyclic ligands, neutral group 4 metal $\left(\mathrm{N}_{4}\right) \mathrm{MR}_{2}$ complexes, and cationic mono-alkyl $\left(\mathrm{N}_{4}\right) \mathrm{M}(\mathrm{R})^{+}$species. Initial indications are that the latter will be highly reactive in base-free form.

\section{Publications, 1992}

(42) "Reaction of Cationic $\mathrm{Zr}$ Alkyl Complexes with $\mathrm{CH}_{3} \mathrm{CN}$, II. Competition Between Insertion and $\beta$ H Elimination." Y. W. Alelyunas, Z. Guo, R. E. LaPointe, and R. F. Jordan, Organometallics submitted.

(39) "Chemistry of New Electrophilic Metal Alkyl Compounds", R. F. Jordan, Makromol. Chem., Macromol. Symp. 1992, IN PRESS.

(36) "Structural Characterization of $\mathrm{Cp}^{*} \mathrm{Hf}\left(\mathrm{CH}_{2} \mathrm{Ph}\right)_{3}$. Evidence for an $\alpha$-Agostic Interaction." Z. Guo, D. J. Crowther, N. C. Baenziger, R. F. Jordan, Organometallics, submitted.

(34) "THF Ring-Opening and $H / D$ Exchange Reactions of $\left(\mathrm{C}_{5} \mathrm{H}_{4} \mathrm{Me}\right)_{2} \mathrm{Zr}(\mathrm{H})(\mathrm{THF})^{+}$. Evidence for Hydrogenolysis of Zr-Cp Bonds." Z. Guo, P. K. Bradley, and R. F. Jordan, Organometallics, 1992, $11,2690$.

\section{Research Plan for 1993}

In the upcoming year we will focus our attention on developing the chemistry of base-free, group 4 metal $\left(\mathrm{N}_{4}\right) \mathrm{MR}^{+}$complexes. We will also investigate the synthesis and chemistry of neutral group 3 and lanthanide metal analogues. In parallel work we will investigate related $\left(N_{4}\right) M=C R_{2}$ and $\left(N_{4}\right) M=O$ alkylidene and oxo systems. When metal/ligand combinations which promote high reactivity are discovered, we will turn our attention to chiral systems, probably derived from 6 above, for asymmetric catalysis. Additionally we will begin studies of mono-Cp cations, $\mathrm{CpMR}_{2}{ }^{+}$which we expect to be highly electrophilic due to the 10 -electron configuration. 


\section{Statement of Expected Expenditures}

It is anticipated that all remaining funds for the current budget year will be expended before 12/31/92.

\section{DISCLAIMER}

This report was prepared as an account of work sponsored by an agency of the United States Government. Neither the United States Government nor any agency thereof, nor any of their employees, makes any warranty, express or implied, or assumes any legal liability or responsibility for the accuracy, completeness, or usefulness of any information, apparatus, product, or process disclosed, or represents that its use would not infringe privately owned rights. Reference herein to any specific commercial product, process, or service by trade name, trademark, manufacturer, or otherwise does not necessarily constitute or imply its endorsement, recommendation, or favoring by the United States Government or any agency thereof. The views and opinions of authors expressed herein do not necessarily state or reflect those of the United States Government or any agency thereof. 

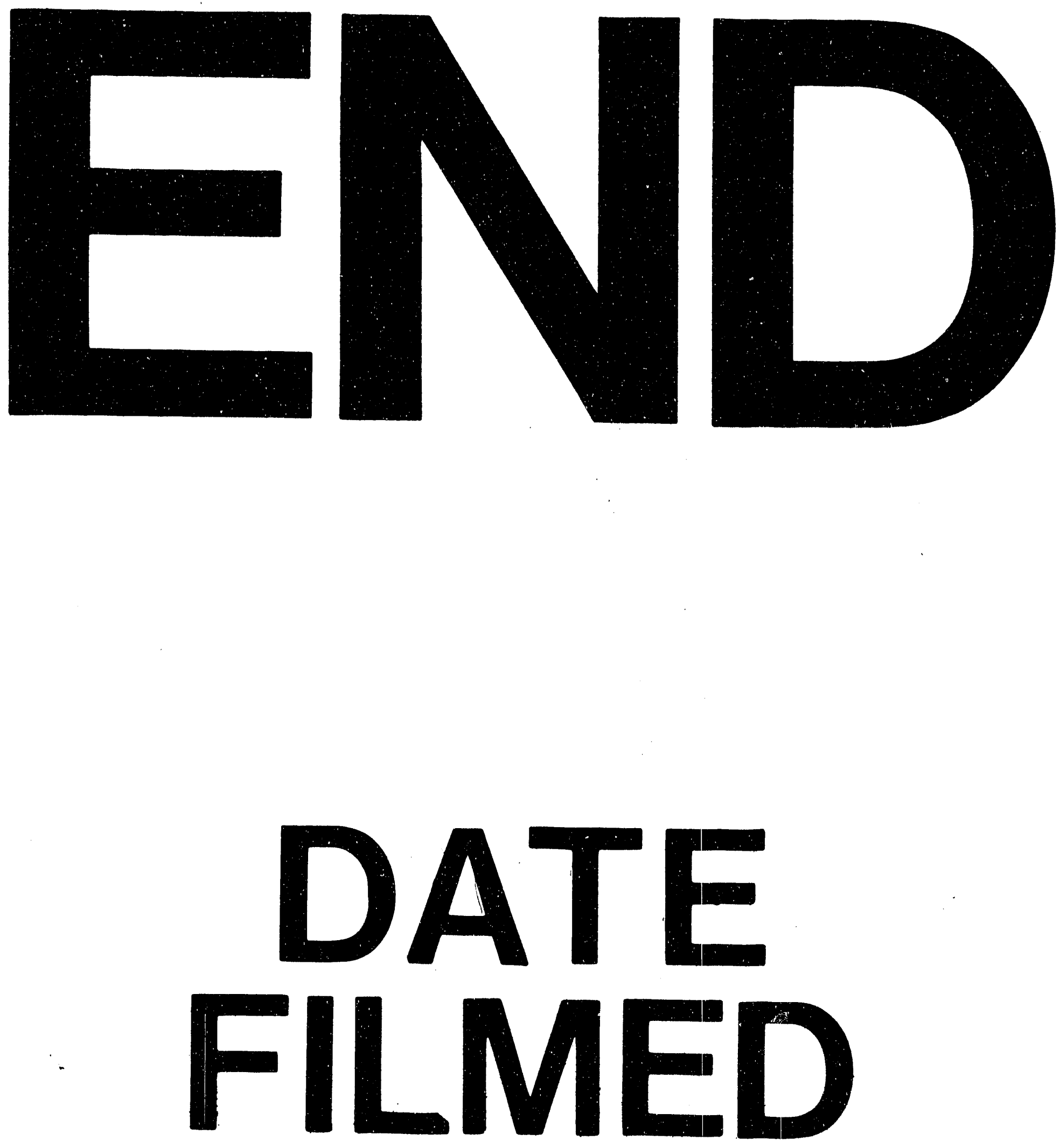

I

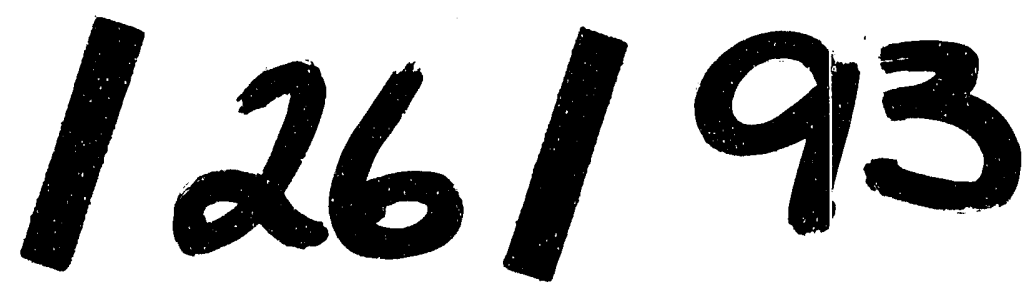


